\title{
Insights into Multifractal Characterization of Coals by Mercury Intrusion Porosimetry
}

\author{
Sijian Zheng ${ }^{1,2,3, *}$, Yanbin Yao ${ }^{1,2} \mathbb{C}^{\text {, Shasha Zhang }}{ }^{4}$, Yong Liu ${ }^{1,2}$ and Jinhui Yang ${ }^{5}$ \\ 1 School of Energy Resource, China University of Geosciences, Beijing 100083, China; yyb@cugb.edu.cn (Y.Y.); \\ 3006180051@cugb.edu.cn (Y.L.) \\ 2 Coal Reservoir Laboratory of National Engineering Research Center of CBM Development \& Utilization, \\ China University of Geosciences, Beijing 100083, China \\ 3 Beijing Key Laboratory of Unconventional Natural Gas Geological Evaluation and Development \\ Engineering, Beijing 100083, China \\ 4 College of Chemistry, Nankai University, Tianjin 300071, China; 2120170933@mail.nankai.edu.cn \\ 5 Beijing Oil and Gas Pipeline Control Center, Beijing 100083, China; yangjhbogc@petrochina.com \\ * Correspondence: sijian.zheng@cugb.edu.cn
}

Received: 17 November 2019; Accepted: 10 December 2019; Published: 12 December 2019

\begin{abstract}
Mercury intrusion porosimetry (MIP) as a practical and effective measurement has been widely used in characterizing the pore size distribution (PSD) for unconventional reservoirs (e.g., coals and shales). However, in the process of MIP experiments, the high mercury intrusion pressure may cause matrix compressibility and result in inaccurate estimations of PSD. To get a deeper understanding of the variability and heterogeneity characteristics of the actual PSD in coals, this study firstly corrected the high mercury intrusion pressure data in combination with low-temperature $\mathrm{N}_{2}$ adsorption (LTNA) data. The results show that the matrix compressibility was obvious under the pressure over $24.75 \mathrm{MPa}$, and the calculated matrix compressibility coefficients of bituminous and anthracite coals range from 0.82 to $2.47 \times 10^{-10} \mathrm{~m}^{2} / \mathrm{N}$. Then, multifractal analysis was introduced to evaluate the heterogeneity characteristics of coals based on the corrected MIP data. The multifractal dimension $D_{\min }$ is positively correlated with vitrinite content, but negatively correlated with inertinite content and mercury intrusion saturation. The multifractal dimension $D_{\max }$ shows negative relationships with moisture and ash content, and it also emerges as a "U-shaped" trend with efficiency of mercury withdrawal. It is concluded that multifractal analysis can be served as a practical method not only for evaluating the heterogeneity of coal PSDs, but also for other unconventional reservoirs (e.g., shale and tight sandstone).
\end{abstract}

Keywords: coalbed methane (CBM); multifractal analysis; pore size distribution (PSD); low-temperature $\mathrm{N}_{2}$ adsorption (LTNA); heterogeneity

\section{Introduction}

The pore size distribution (PSD) properties of coals play an important role in characterizing coal reservoirs since it has significant effects on the exploration coalbed methane (CBM) [1-4]. To simplify the study, we define the "pores" as all pore void types in the coal, including fractures (large extending length but small pore aperture), macropore (pore diameter $>1000 \mathrm{~nm}$ ), mesopore $(100-1000 \mathrm{~nm})$, transitional pore $(10-100 \mathrm{~nm})$ and micropore $(<10 \mathrm{~nm})$, as stated by Hodot in 1966. In recent decades, various constantly updated methods have been applied to evaluate the coal PSD characteristics, including direct observational methods and indirectly inferred methods. Direct observation methods are, for example, scanning electron microscopy (SEM) [5,6], X-ray computerized tomography (X-CT) $[7,8]$ and atomic force microscope (AFM) $[9,10]$, which can be used 
to characterize the two- or three-dimensional distribution of coal PSDs. Indirectly inferred methods include mercury intrusion porosimetry (MIP) [11,12], gas adsorption $\left(\mathrm{N}_{2}\right.$ and $\left.\mathrm{CO}_{2}\right)$ [13-16] and nuclear magnetic resonance (NMR) [17-19]. Among of these methods, MIP measurement has been proven as an effective method to estimate the PSD of coals. However, in the process of MIP experiments, the high mercury intrusion pressure may cause coal matrix compressibility and result in inaccurate estimation of coal PSDs [20,21]. Thus, before characterizing coal PSDs only by MIP measurement, the effects of matrix compressibility in a high mercury intrusion pressure range ought to be considered first.

Previous studies have shown that it is a feasible method to evaluate coal matrix compressibility by combining low-temperature $\mathrm{N}_{2}$ adsorption (LTNA) and MIP data [22-24]. By using this method, Guo et al. [23] calculated the coal matrix compressibility coefficients and found it emerges as a "U-shaped" trend with coal ranks. Cai et al. [24] found the coal matrix compressibility coefficients are in the range of $0.24-13.56 \times 10^{-10} \mathrm{~m}^{2} / \mathrm{N}$, and then they revealed the influence factors of compressibility in differently ranked coals.

The PSD of the porous mediums are commonly not homogeneous distributed in a three-dimensional space, which makes it hard to describe its heterogeneity characteristics by using conventional Euclidean geometry. Fractal analysis, proposed by Mandelbrot [25], has been proven as an important and effective tool for evaluating the physical-geometrical properties of spatially non-uniform system [26-29]. The sporadic distribution of objects can be described by fractal dimension (D), which can be expressed as

$$
D=\lim _{\delta \rightarrow 0}-\frac{\log N(\delta)}{\log \delta}
$$

where $\delta$ is the size of the box; and $N(\delta)$ is the number of boxes with the same size of $\delta$.

Previous studies have shown that porous rocks are usually with good self-similar characteristics, which can quantitatively describe the complexity of pore structures by fractal analysis. For example, Krohn and Thompson [30] analyzed the fractal characteristics of sandstones by SEM technique and found that the fractal dimension shows a positive relationship with porosity. Yao et al. [13] conducted fractal analysis by using LTNA measurements and revealed that less heterogeneity in pore structures indicates a higher methane adsorption capacity of coals. Peng et al. [31] found that fractal analysis can be used to estimate the rock pore radius based on the CT image fractal results. Zheng et al. [4] presented a novel method for characterization of full-scale PSD, porosity and permeability of coals by combining an NMR technique and fractal analysis.

However, studies have shown that the conventional single fractal method has its drawbacks, because it is incapable to describe the local portion heterogeneity distribution of an object [32-35]. Multifractal analysis is regarded as an extension of single fractal theory, which can overcome the limitations of the single fractal theory and characterize the variability and heterogeneity in more detail. Ge et al. [34] investigated the multifractal distribution of pore space and developed a valid method for PSD classification for tight reservoirs. Zhao et al. [29] combined multifractal analysis with NMR technique to investigate the heterogeneity distribution of tight sandstone reservoirs. Zhao et al. [36] revealed the multifractal characterization of PSDs for Middle Bakken by using LTNA and NMR measurements. Zheng et al. [37] presented a novel method to determine NMR $T_{2}$ cutoff values by applying multifractal analysis for coals. By combining MIP measurement and multifractal analysis, Li et al. [38] investigated the variability and heterogeneity of tectonically deformed coals with $R_{0, m}$ (mean maximum vitrinite reflectance) in the range of $1.72 \%$ to $1.86 \%$, and then found that multifractal analysis can be served as a useful method for describing the internal heterogeneity characteristics of PSD. However, the coal samples studied in Li et al. [38] are only low volatile bituminous coal, which limit the application of multifractal analysis in sub-bituminous and anthracite coal.

In this study, we performed MIP and LTNA experiments on 15 different coal ranks collected from the southern Junngar basin and Qinshui basin. Combining MIP and LTNA data, the coal matrix compressibility coefficients were determined first. Then, based on the determined coal matrix 
compressibility coefficients, the PSDs from MIP measurement were corrected. Finally, multifractal analysis was applied in describing the heterogeneity characterizations for the corrected coal PSDs.

\section{Samples and Experiments}

Fifteen coal samples were taken from the underground mines in the southern Junggar basin and Qinshui basin, and then quickly carried to the lab for basic petrophysical analysis, as well as MIP and LTNA analysis. The analysis results of vitrinite reflectance, maceral composition and proximate analysis are given in our previous studies [19].

MIP measurements were conducted with the Micromeritics Autopore 9520 instrument, that can automatically record mercury intrusion pressure, pore size and mercury intrusion volume. For sample preparation, based on the Standard SY/T 5346-2005, the coal sample size required was approximately $2 \mathrm{~mm}$. The mercury intrusion pressure with an interval of 0.012-206.825 MPa corresponded to a pore size of $50-0.03 \mu \mathrm{m}$.

LTNA analyses were performed using the Micromeritics ASAP 2020N. For sample preparation, the coal samples were crushed into the size of 60-80 mesh. Then, the coal powders were dried at $110{ }^{\circ} \mathrm{C}$ for $12 \mathrm{~h}$ in a drying oven to remove moisture. After drying, all coal powders were evacuated for complete outgassing in a high vacuum system within $5 \mathrm{~h}$. Lastly, the coal powders for quantitative adsorption isotherm analyzing were measured at $-196^{\circ} \mathrm{C}$ with a relative pressure of of $0.011-0.995 \mathrm{MPa}$.

\section{Multifractal Analysis}

Different to single fractal analysis, multifractal analysis cannot describe self-similarity by a single fractal dimension, but rather by a continuous function (i.e., multifractal spectrum). More detailed information about the principle of multifractal analysis can be found in previous studies [12,33,35,38]. Here, we just made a brief introduction to multifractal analysis by using the box-counting method. Based on the cardinal theory of the box-counting method, a cubic box with a size of $\delta \times \delta$ can be used to cover the pore volume of objects. As a result, the objects can be divided into $N(\delta)$ boxes. Thus, the probability mass distribution $P_{i}(\delta)$ in the $i$ th box can be defined as

$$
P_{i}(\delta)=\frac{N_{i}(\delta)}{\sum_{i=1}^{N(\delta)} N_{i}(\delta)}
$$

where $N_{i}(\delta)$ is the pore volumes in the $i$ th box.

For a target object with a multifractal property, the probability mass distribution $P_{i}(\delta)$ follows a power-law equation with scale $\delta$ :

$$
P_{i}(\delta) \propto \delta^{\alpha_{i}}
$$

where $\alpha_{i}$ is the singularity strength in the $i$ th box.

Possibly, there are many boxes that have the same value of $\alpha$. Here, the number of boxes having a singularity strength range of $\alpha+d a$ was represented as $N_{\alpha}(\delta)$, then:

$$
N_{\alpha}(\delta) \propto \delta^{-f(\alpha)}
$$

where $f(\alpha)$ is the multifractal spectrum and can achieve the maximum value when

$$
\frac{d f(\alpha(q))}{d \alpha(q)}=0
$$

where $q$ is the moment order and can be any real number in the range of $[-\infty,+\infty]$. 
The partition function for the moment order $q$ was denoted as $X(q, \delta)$. Then:

$$
X(q, \delta)=\sum_{i=1}^{N_{i}} P_{i}^{q}(\delta) \propto \varepsilon^{-(q-1) D_{q}}
$$

where $D_{q}$ is the multifractal dimension for the moment order $q$. When $q \neq 1, D_{q}$ can be expressed as

$$
D_{q}=\frac{1}{q-1} \lim _{\delta \rightarrow 0} \frac{\log \sum_{i=1}^{N(\delta)} P_{i}^{q}(\delta)}{\log \delta}
$$

When $q=1$, Equation (7) does not make mathematical sense. $D_{1}$ can be determined by L'Hôpital rules:

$$
D_{1}=\lim _{\delta \rightarrow 0} \frac{\sum_{i=1}^{N(\delta)} P_{i}(\delta) \log P_{i}(\delta)}{\log \delta}
$$

The mass exponent $\tau(q)$ which related to multifractal dimension $D_{q}$ [39]:

$$
(q)=(1-q) D_{q}
$$

The singularity strength $\alpha(q)$ and multifractal spectrum $f(\alpha)$ can be evaluated by the Legendre transformation:

$$
\begin{gathered}
\alpha(q)=\frac{d \tau(q)}{d q} \\
f(\alpha)=q \alpha(q)-\tau(q)
\end{gathered}
$$

The singularity strength range $\Delta \alpha$, commonly used as an indicator to describe the heterogeneity characteristic of subjects, is defined as

$$
\Delta \alpha=\alpha_{\max }-\alpha_{\min }
$$

where $\alpha_{\max }$ and $\alpha_{\min }$ are the maximum and minimum values of the singularity strength, respectively.

\section{Results and Discussion}

\subsection{Pore Structures by MIP and LTNA Measurement}

As shown in Figure 1 and Table 1, the mercury intrusion and extrusion curves of the MIP measurements for the selected coal samples are classified into three types. For type I, represented by sample L2, there is a large hysteresis loop between the intrusion and extrusion curves, indicating good development of fractures and macro pores. For type II, represented by sample M5, the intruded mercury increases rapidly when the intrusion pressure $>10 \mathrm{MPa}$, which means good connectivity of the macro pores but poor connectivity of the micropores. For type III, represented by sample H3, there is low intruded mercury saturation, indicating the connectivity between the macro pores and the micropores is very poor.

Figure 2 and Table 1 show the three typical types of nitrogen adsorption/desorption curves at $77 \mathrm{~K}$ according to the IUPAC classification. For type I, represented by sample L2, an evident hysteresis loop occurring at a relative pressure range of $0.4-1 \mathrm{MPa}$, indicating that the ink bottle-like pores are well developed in Type I. For Type II, represented by sample M5, the adsorption curve shows a slight increase when the relative pressure is less than 0.8 , while it emerged that there is a significant increase when the relative pressure approaches to 1 . The desorption curve is similar to the adsorption curve, indicating the pore morphology is plate-like pores. For Type III, represented by sample H3, the adsorption curve looks like type II. While for the desorption curve, there is a significant hysteresis 
loop occurring at a relative pressure range of $0.7-1 \mathrm{MPa}$. This indicates the pore morphology of type III is cylinder-like pores.

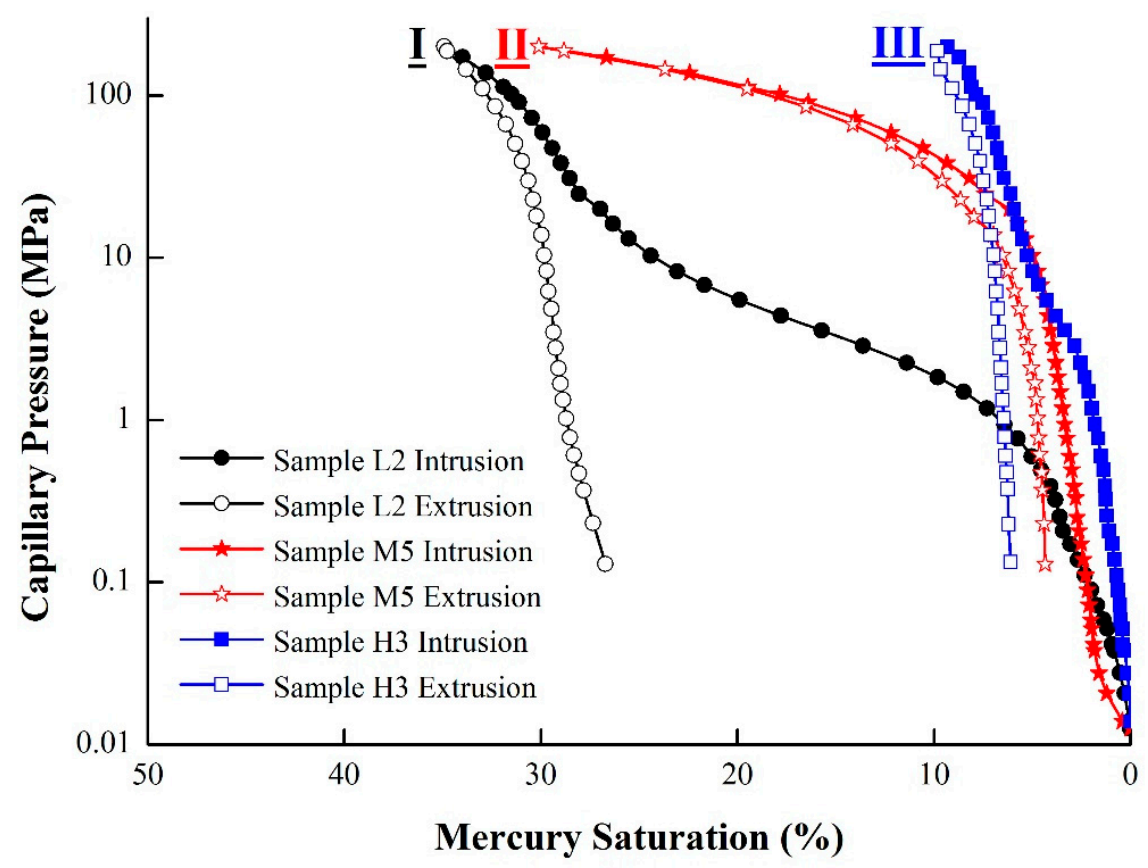

Figure 1. Mercury intrusion/extrusion curves of the represented coals. Reprint with permission [19]; 2019, Int. J. Coal Geol.

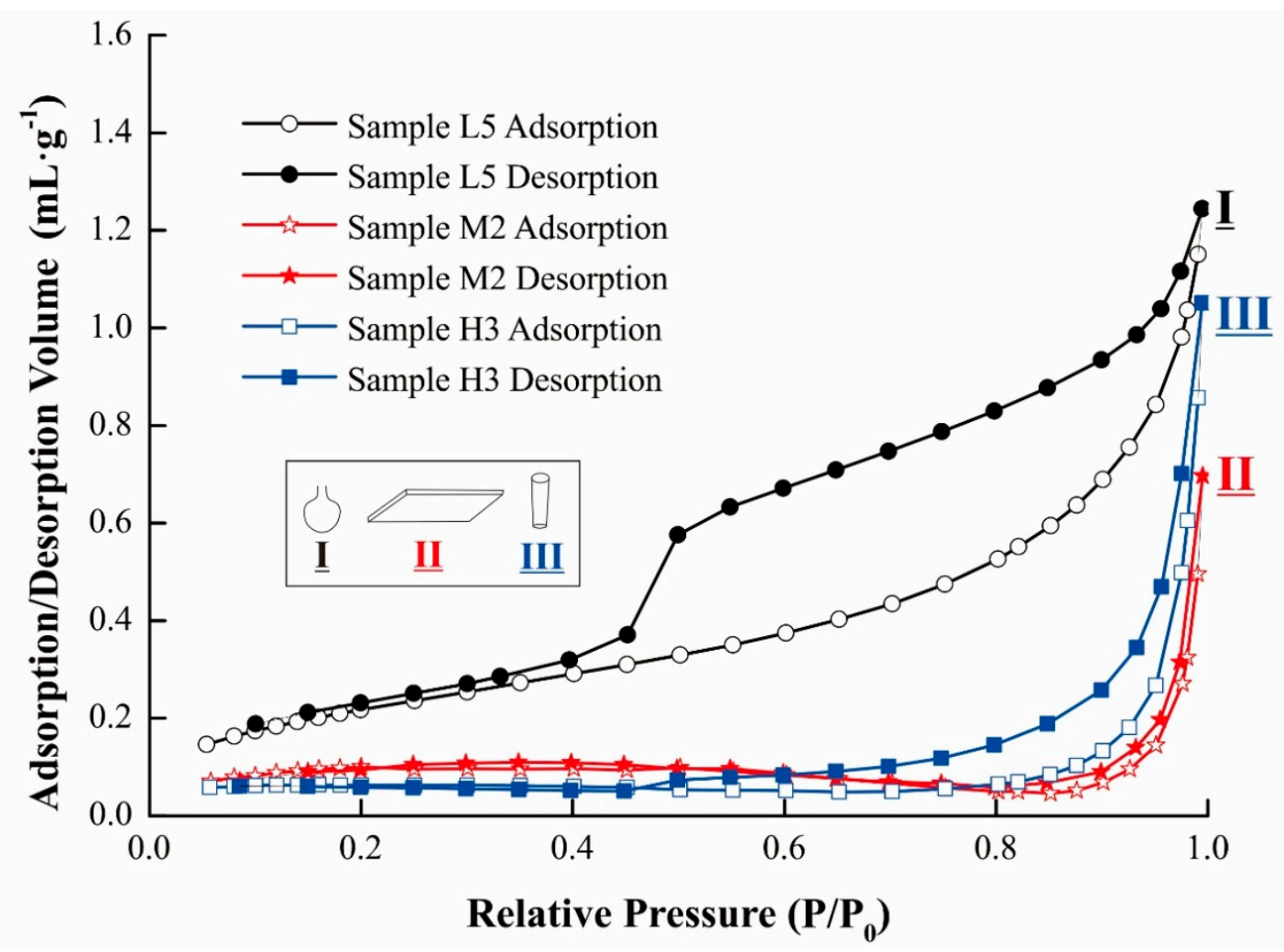

Figure 2. LTNA adsorption/desorption curves of the represented coals. Reprint with permission [19]; 2019, Int. J. Coal Geol. 
Table 1. Mercury intrusion porosimetry (MIP) and low-temperature $\mathrm{N}_{2}$ adsorption (LTNA) results for the selected coals.

\begin{tabular}{|c|c|c|c|c|c|c|c|c|c|}
\hline \multirow[b]{2}{*}{$\begin{array}{l}\text { Sample } \\
\text { No. }\end{array}$} & \multicolumn{6}{|c|}{ MIP Results } & \multicolumn{3}{|c|}{ LTNA Results } \\
\hline & $\begin{array}{l}\text { True Density } \\
\qquad\left(\mathrm{g} / \mathrm{cm}^{3}\right)\end{array}$ & $\begin{array}{l}\text { IMS } \\
(\%)\end{array}$ & $\begin{array}{c}\text { EMW } \\
(\%)\end{array}$ & $\begin{array}{c}K_{\mathrm{c}} \times 10^{-10} \\
\left(\mathrm{~m}^{2} / \mathrm{N}\right)\end{array}$ & $\begin{array}{c}\varepsilon \\
\left(\times 10^{-4}\right)\end{array}$ & $\begin{array}{l}\text { Type of } \\
\text { Curve }\end{array}$ & $\begin{array}{l}\text { BJH Pore Volume } \\
\left(10^{-3} \mathrm{~cm}^{3} / \mathrm{g}\right)\end{array}$ & $\begin{array}{l}\text { Pore Volume in 3-25 } \\
\mathrm{nm}\left(10^{-3} \mathrm{~cm}^{3} / \mathrm{g}\right)\end{array}$ & $\begin{array}{l}\text { Type of } \\
\text { Curve }\end{array}$ \\
\hline L2 & 1.21 & 34.92 & 23.49 & 2.23 & 2.00 & I & 16.11 & 2.09 & III \\
\hline L3 & 1.36 & 36.53 & 73.11 & 2.17 & 0.80 & II & 9.10 & 0.68 & I \\
\hline $\mathrm{L} 4$ & 1.27 & 43.67 & 71.56 & 1.83 & 2.00 & I & 1.25 & 1.01 & III \\
\hline M2 & 1.43 & 39.17 & 66.95 & 1.25 & 0.60 & I & 1.08 & 0.16 & II \\
\hline M3 & 1.70 & 9.74 & 37.96 & 1.12 & 0.50 & III & 2.73 & 0.44 & III \\
\hline M4 & 1.37 & 38.62 & 41.86 & 1.21 & 0.80 & I & 16.78 & 3.16 & I \\
\hline M5 & 1.43 & 33.26 & 81.45 & 1.05 & 0.80 & II & 2.27 & 0.37 & III \\
\hline H1 & 1.32 & 37.05 & 69.82 & 1.09 & 1.00 & II & 2.17 & 0.39 & I \\
\hline $\mathrm{H} 2$ & 1.38 & 37.76 & 31.72 & 1.72 & 0.90 & I & 11.67 & 4.56 & I \\
\hline
\end{tabular}

\subsection{Coal Matrix Compressibility Coefficient Calculation.}

Previous studies have shown that the coal matrix compressibility can have a significant influence on the results of MIP experiments when the mercury intrusion pressure is $>20 \mathrm{MPa}[22,24]$. In this study, as shown in Figure 3, it can be found that the cumulative mercury intrusion volume and mercury intrusion pressure shows a good linear relationship when the mercury intrusion pressure is higher than $24.75 \mathrm{MPa}$, and the correlation coefficients are higher than 0.98 for all selected coal samples. This means the coal matrix compressibility effect begins at a mercury intrusion pressure of $24.75 \mathrm{MPa}$. In case of ignoring the compressibility effects of mercury, the coal matrix compressibility coefficient $\left(K_{\mathrm{c}}\right)$ can be expressed as

$$
K_{c}=\frac{d V_{c}}{V_{c} d P}
$$

where $d V_{c} / d P$ represents the coal matrix volume changes as a function of pressure, and $V_{c}$ is the coal matrix volume that can be defined as

$$
V_{c}=\frac{1}{\rho}-V_{B}
$$

where $\rho$ is the true density of coals in $\mathrm{g} / \mathrm{mL}$, and $V_{B}$ is the pore volume evaluated using the $\mathrm{BJH}$ theoretical model by LTNA data in $\mathrm{mL} / \mathrm{g}$.

In the process of MIP measurement, the detected changes of the mercury intrusion volume $\left(\Delta V_{d}\right)$ is commonly due to the changes of the pore filling volume $\left(\Delta V_{p}\right)$ and solid compression volume $\left(\Delta V_{\mathrm{c}}\right)$, which follows a function of

$$
\Delta V_{d}=\Delta V_{p}+\Delta V_{c}
$$

In this study, the high mercury intrusion pressure ranges from $24.75 \mathrm{MPa}$ to $199.94 \mathrm{MPa}$ (corresponding to a pore radius of $25 \mathrm{~nm}$ to $3 \mathrm{~nm}$ based on the Washburn equation). There is a good linear relationship between the cumulative mercury intrusion volume and mercury intrusion pressure (Figure 3). Thus, $\Delta V_{d} / \Delta P$ can be a constant $\varepsilon$ in the mercury intrusion pressure range of $24.75-199.94 \mathrm{MPa}$, and the calculated $\varepsilon$ is listed in Table 1 . In this case, $\Delta V_{c} / \Delta P$ can be redefined as

$$
\frac{\Delta V_{c}}{\Delta P}=\frac{\Delta V_{d}}{\Delta P}-\frac{\Delta V_{p}}{\Delta P}=\varepsilon-\frac{\sum_{3 \mathrm{~nm}}^{25} \Delta V_{p}}{\Delta P}
$$

where $\sum_{3 \mathrm{~nm}}^{25 \mathrm{~nm}} \Delta V_{p}$ is the sum of pore volumes in the pore radius of 3-25 nm, which is calculated by LTNA measurements. 

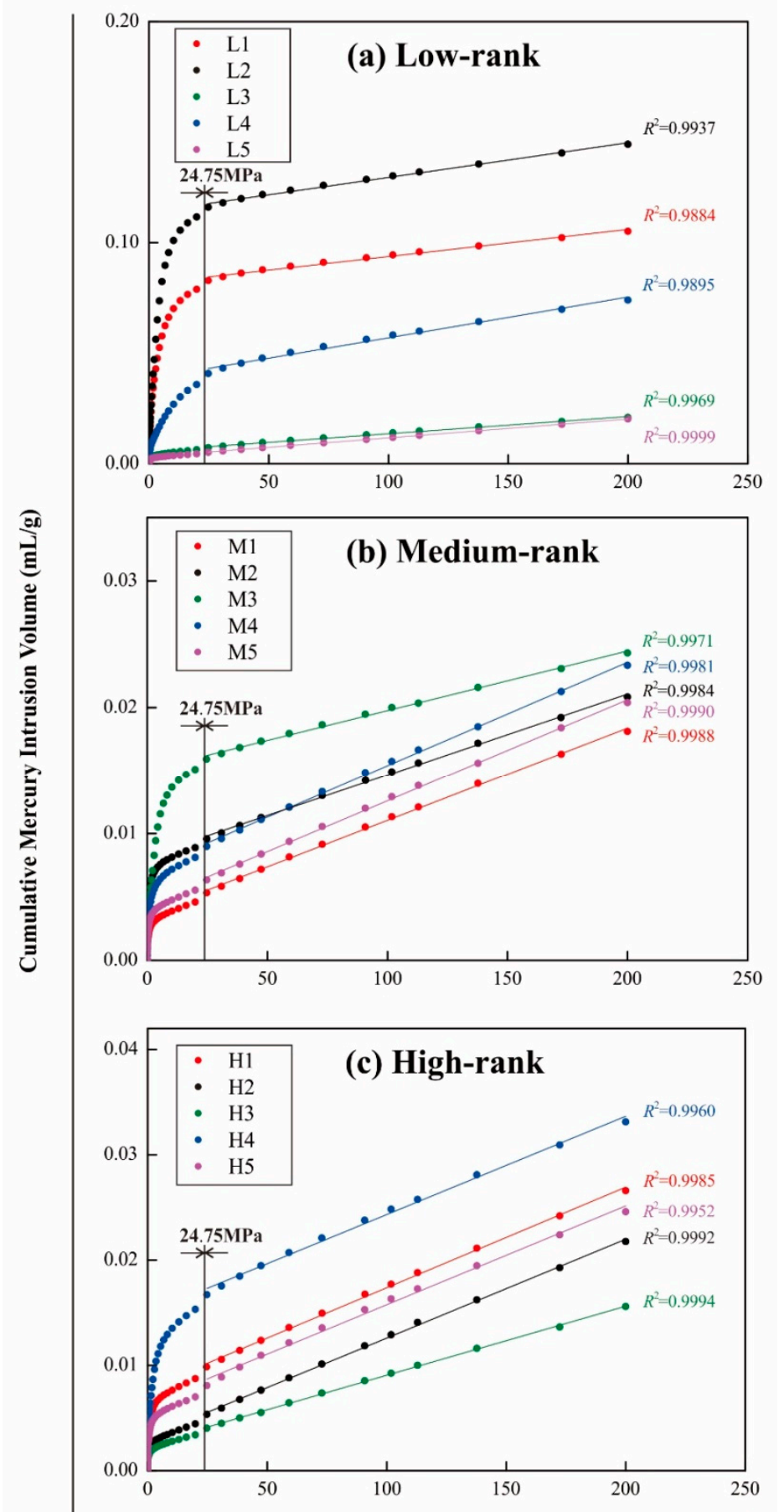

Pressure (MPa)

Figure 3. Cross plots of cumulative mercury intrusion volume vs. pressure for (a) low-rank coals; (b) medium-rank coals; (c) high-rank coals.

Assuming $\Delta V_{c} / \Delta P$ is independent of mercury intrusion pressure, in this case, $d V_{c} / d P$ can be replaced by $\Delta V_{c} / \Delta P$. Hence, the matrix compressibility coefficient can be calculated by combining Equations (13) and (16). In this study, the calculated matrix compressibility coefficient for the selected coal samples is in the range of $0.89-2.47 \times 10^{-10} \mathrm{~m}^{2} / \mathrm{N}$ (Table 1), averaging at $1.21 \times 10^{-10} \mathrm{~m}^{2} / \mathrm{N}$, which is consistent with previous researches, such as Cai et al. [2] $\left(1.55-2.37 \times 10^{-10} \mathrm{~m}^{2} / \mathrm{N}\right)$, Guo et al. [23] $\left(0.35-2.91 \times 10^{-10} \mathrm{~m}^{2} / \mathrm{N}\right)$, and Shao et al. [40] $\left(1.13-3.06 \times 10^{-10} \mathrm{~m}^{2} / \mathrm{N}\right)$. 
Figure 4 displays the cross plot of the coal matrix compressibility coefficients vs. $R_{\mathrm{o}, \mathrm{m}}$. We found that when $R_{\mathrm{o}, \mathrm{m}}$ is less than $1.3 \%$, the coal matrix compressibility coefficients decreases rapidly with increasing $R_{\mathrm{o}, \mathrm{m}}$. It is possible because the mechanical compaction and degasification effect increases with an increase in coalification degree. When $R_{\mathrm{o}, \mathrm{m}}$ is in the range of $1.3-2.5 \%$, the coal matrix compressibility shows an increased trend with an increase in $R_{0, m}$. Because the internal specific surface area of the micropores increases rapidly with the continued increase in coalification degree, the coals become more sensitive to stress. When the $R_{0, m}$ is more than $2.5 \%$, the coal matrix compressibility coefficients increases with increasing $R_{\mathrm{o}, \mathrm{m}}$, since the condensed humus complex and aromatic rings increase [24].

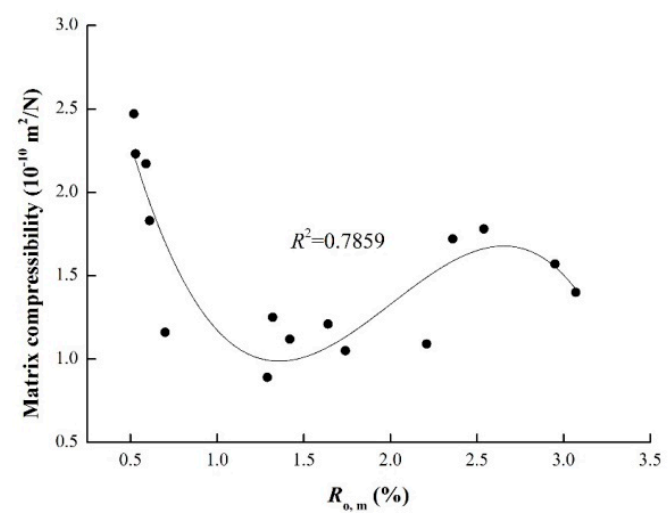

Figure 4. Relationship between the $R_{\mathrm{o}, \mathrm{m}}$ and coal matrix compressibility.

\subsection{Mercury Intrusion Porosimetry Pore Size Distributions Correction}

Previous studies have shown the method to correct the original PSDs of MIP in combination with LTNA data [20,41,42]. As discussed in Section 4.2, the coal matrix compression begins at the mercury intrusion pressure of $24.75 \mathrm{MPa}$. Thus, in this study, the pressure range for the MIP data correction is 24.75-199.94 MPa. The pore volume in this stage can be redefined as

$$
\Delta V_{p i}=\Delta V_{d(p i)}-\Delta V_{m(p i)}=V_{d(p i)}-V_{d(p 0)}-k_{c} V_{c(p i)}\left(p_{i}-p_{0}\right)
$$

where $\Delta V_{p i}, \Delta V_{d(p i)}$ and $\Delta V_{m(p i)}$ are the changes of filling pore volume, detected mercury volume, and matrix compression volume when pressure increases from $p_{0}$ to $p_{i}$, respectively; $V_{d(p i)}$ represents the detected mercury intrusion volume at a pressure of $p_{i}$; and $V_{c(p i)}$ is the coal matrix compressed volume, which can be defined as

$$
V_{c(p i)}=V_{c}-\frac{d V_{c}}{d P}\left(p_{i}-p_{0}\right)
$$

Combining Equations (17) and (18), the corrected mercury intrusion data and PSDs from MIP measurements for all selected coal samples are shown in Figure 5. Compared with the uncorrected mercury intrusion volume in a pore radius of $3-25 \mathrm{~nm}$, the corrected mercury intrusion volume decreased by $35.51-96.65 \%$. This indicates that the matrix compressibility has an evident impact on coal PSDs estimation. By using MIP measurement, previous studies evaluated the heterogeneity characteristics of coals only through the original PSDs data and single fractal method [43,44], rather than the corrected PSDs data and multifractal analysis. This may result in inaccuracy estimation of the variability and heterogeneity of coals. In the next section, based on the corrected PSDs from MIP measurement, the heterogeneity characteristics of coals were investigated by the introduced multifractal analysis. 

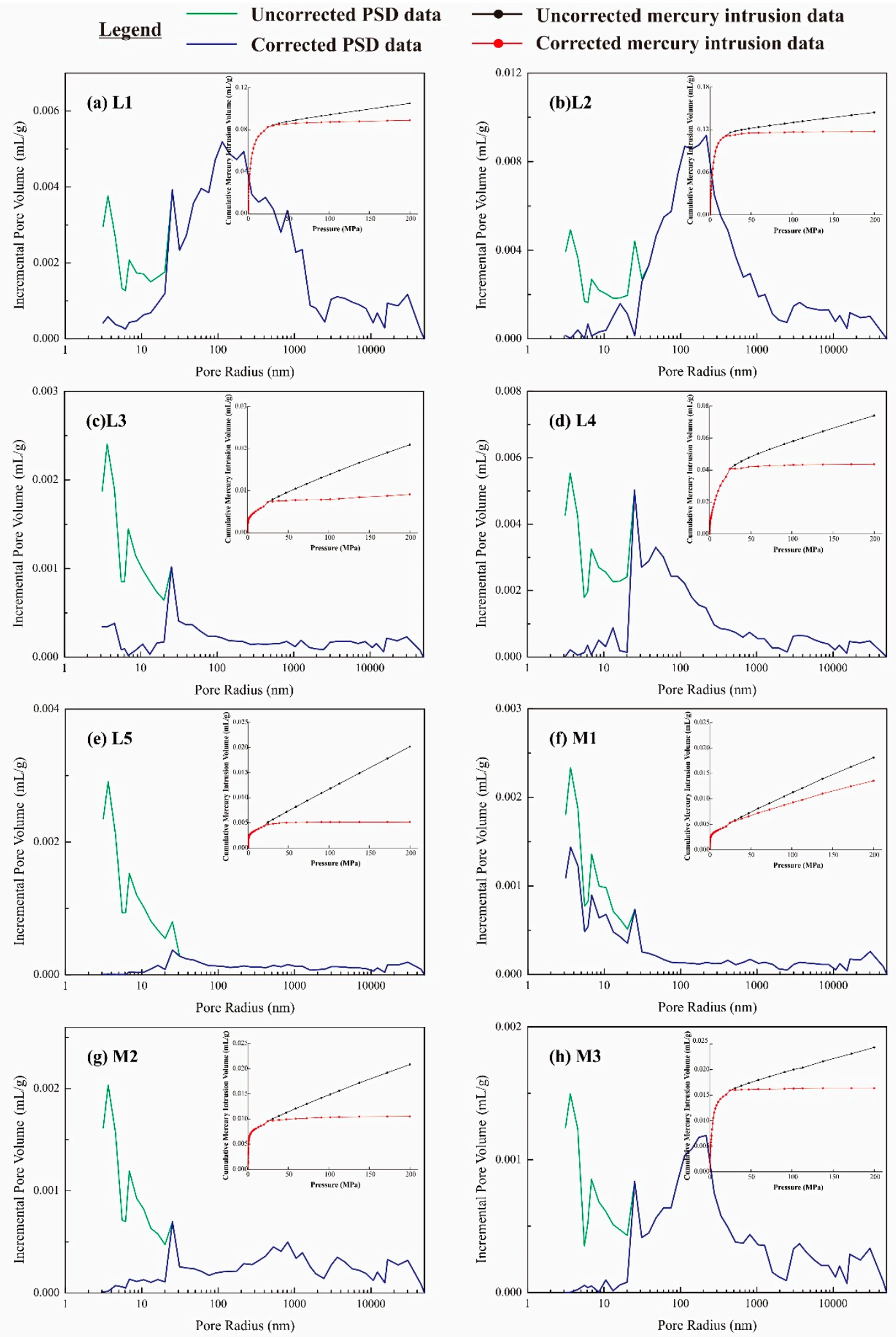

Figure 5. Cont. 

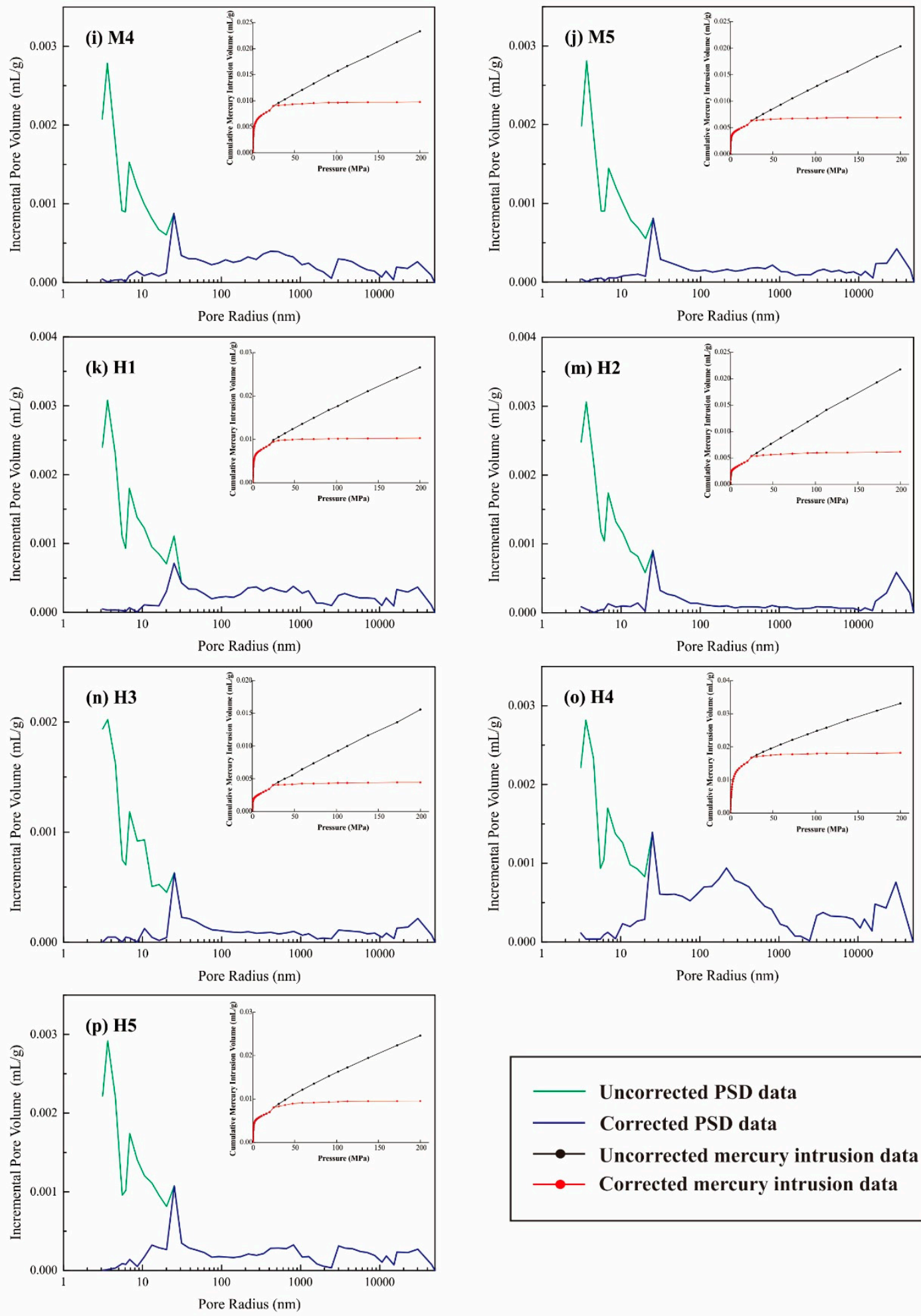

Figure 5. Comparisons between the uncorrected and corrected pore size distributions (PSDs) of the coals from MIP measurements. (a) sample L1; (b) sample L2; (c) sample L3; (d) sample L4; (e) sample L5; (f) sample M1; (g) sample M2; (h) sample M3; (i) sample M4; (j) sample M5; (k) sample H1; (m) sample $\mathrm{H} 2$; (n) sample H3; (o) sample H4; (p) sample H5. 


\subsection{Multifractal Characteristics of the Corrected Pore Size Distributions}

Figure 6 shows the double log relationship between $X(q, \varepsilon)$ and $\varepsilon$ for the presentative sample L2. We find that the $\log X(q, \varepsilon)$ shows a great linear relationship with $\log (\varepsilon)$, with the correlation coefficients higher than 0.99 for all $q$ values. This indicates the corrected PSDs for the presentative sample has multifractal characteristics.

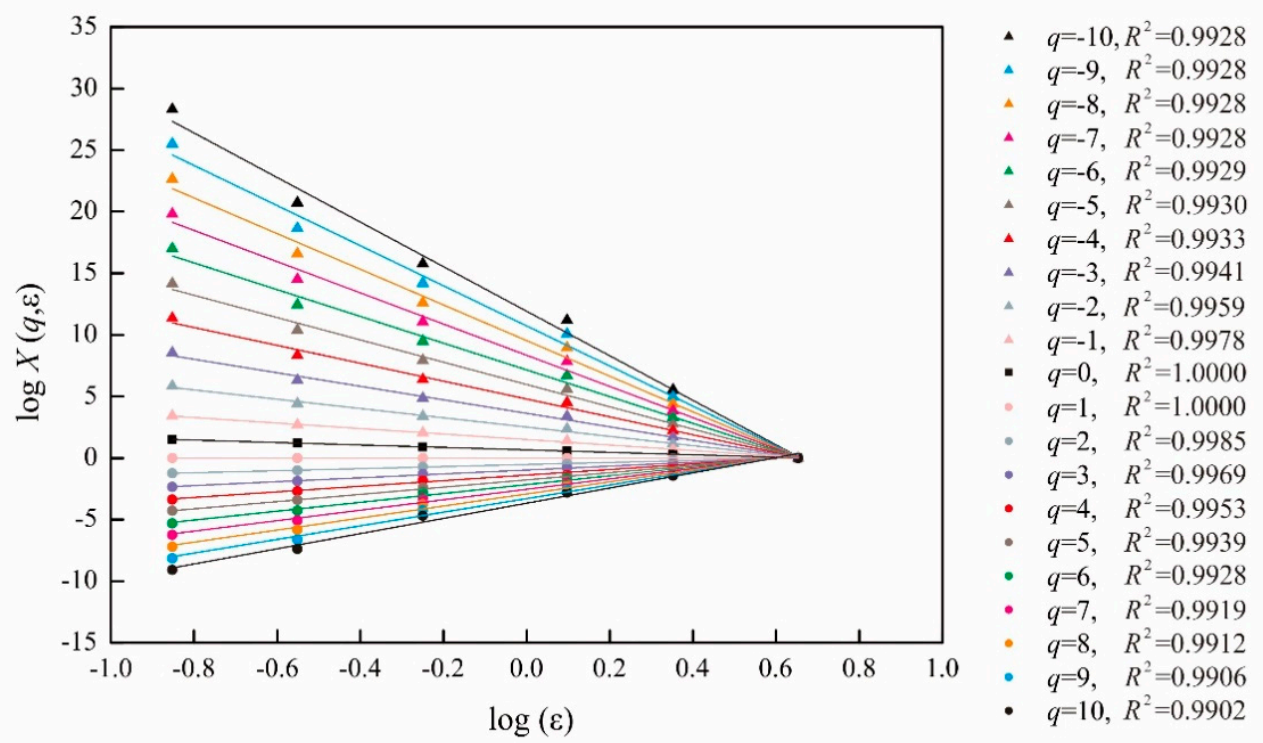

Figure 6. Log plots of the partition function, $X(q, \varepsilon)$, versus box size, $\varepsilon$, of the coal named L2.

Figure 7 shows the cross plots of generalized dimension $\left(D_{q}\right)$ and $q$ (i.e., generalized dimension spectrum) for all selected coal samples. We found that all generalized dimension spectra show an inverse S-shaped. When $q<0, D_{q}$ decreases sharply with the increases of $q$. On the contrast, $D_{q}$ decreases slightly with the increases of $q$ when $q>0$.

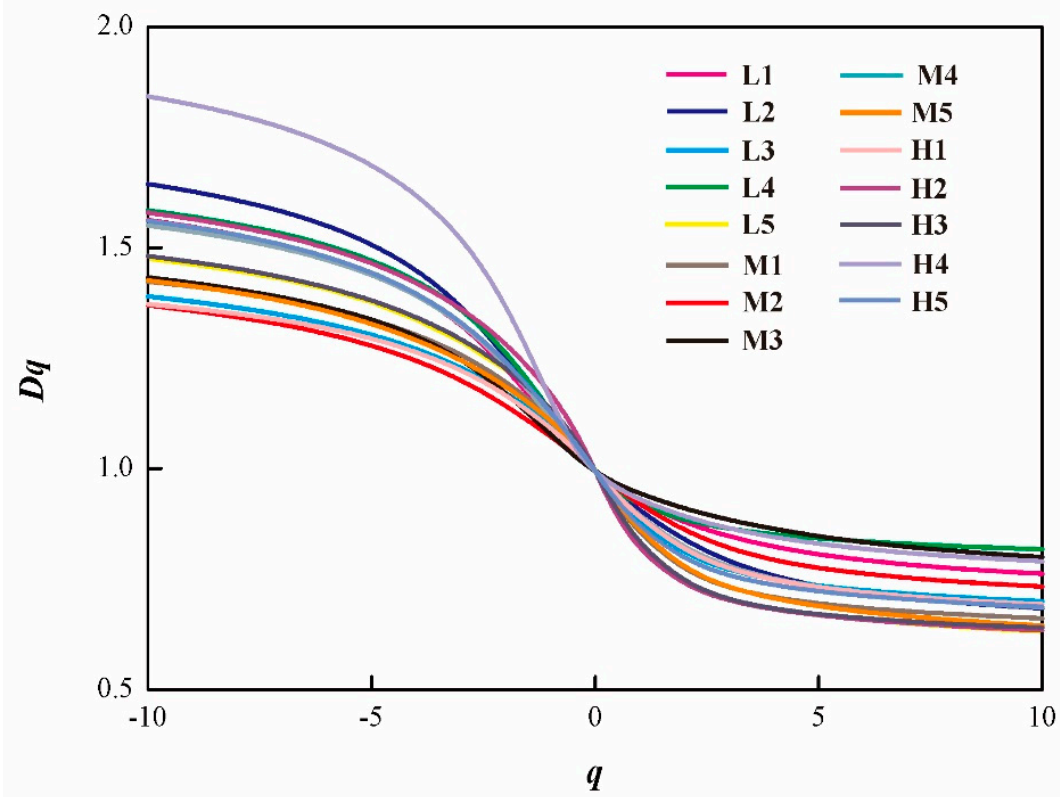

Figure 7. Generalized dimension $\left(D_{q}\right)$ versus variable $q$ from $q=-10$ to $q=10$.

$D_{0}, D_{1}$ and $D_{2}$ are known as the capacity dimension, information dimension, and correlation dimension, respectively $[45,46]$. The calculated values of $D_{0}, D_{1}$, and $D_{2}$ are presented in Table 2 . 
$D_{\min }$ and $D_{\max }$ values for all coals range from 1.358 to 1.825 (average at 1.500), 0.626 to 0.818 (average at 0.704), respectively (Table 2).

Table 2. Multifractal parameters by multifractal analysis of the selected coal samples.

\begin{tabular}{ccccccc}
\hline Sample No. & $\boldsymbol{D}_{-\mathbf{1 0}}$ & $\boldsymbol{D}_{\mathbf{0}}$ & $\boldsymbol{D}_{\mathbf{1}}$ & $\boldsymbol{D}_{\mathbf{2}}$ & $\boldsymbol{D}_{\mathbf{1 0}}$ & $\boldsymbol{\Delta} \boldsymbol{\alpha}$ \\
\hline L1 & 1.548 & 1.000 & 0.924 & 0.878 & 0.762 & 1.002 \\
L2 & 1.628 & 1.000 & 0.905 & 0.837 & 0.685 & 1.169 \\
L3 & 1.379 & 1.000 & 0.879 & 0.807 & 0.700 & 0.866 \\
L4 & 1.571 & 1.000 & 0.918 & 0.883 & 0.818 & 0.952 \\
L5 & 1.457 & 1.000 & 0.828 & 0.739 & 0.626 & 1.032 \\
M1 & 1.423 & 1.000 & 0.852 & 0.768 & 0.661 & 0.941 \\
M2 & 1.358 & 1.000 & 0.919 & 0.859 & 0.733 & 0.816 \\
M3 & 1.421 & 1.000 & 0.943 & 0.909 & 0.800 & 0.825 \\
M4 & 1.537 & 1.000 & 0.892 & 0.819 & 0.686 & 1.068 \\
M5 & 1.414 & 1.000 & 0.858 & 0.772 & 0.645 & 0.971 \\
H1 & 1.362 & 1.000 & 0.888 & 0.813 & 0.693 & 0.858 \\
H2 & 1.565 & 1.000 & 0.813 & 0.734 & 0.634 & 1.127 \\
H3 & 1.468 & 1.000 & 0.827 & 0.740 & 0.640 & 1.020 \\
H4 & 1.825 & 1.000 & 0.930 & 0.891 & 0.790 & 1.279 \\
H5 & 1.547 & 1.000 & 0.867 & 0.793 & 0.688 & 1.067 \\
\hline
\end{tabular}

Figure 8 represents the relationship between the $f(\alpha)$ and $\alpha(q)$ (i.e., multifractal spectra). The multifractal spectrum shows a typical shape of a concave-down parabola. On the left of the parabola, $f(\alpha)$ increases with the increase of $\alpha(q)$. In contrast, $f(\alpha)$ decreases with the increase of $\alpha$ $(q)$ on the right of parabola. The values of singularity strength range $(\Delta \alpha)$ range from 0.816 to 1.279 , average at a high value of 1.000 (Table 2), indicating the variability and heterogeneity characteristics of the corrected PSDs. Considering the similar pore structure characterization in some unconventional reservoirs, the multifractal analysis used in this study (i.e., coal) can also be applied for shales and tight sandstone PSD heterogeneity investigations.

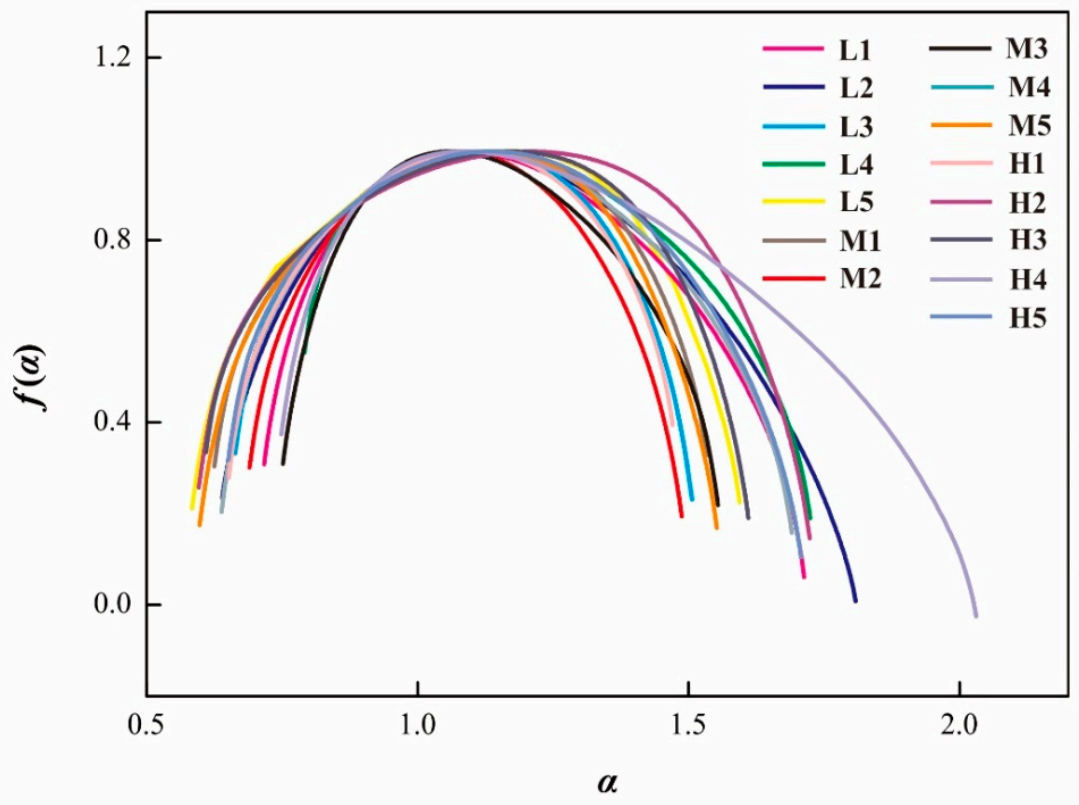

Figure 8. The relationship between the $f(\alpha)$ and $\alpha(q)$, i.e., multifractal spectra of all coals.

Figure 9 displays the relationship of $\tau(q)$ and $q$ (i.e., mass exponent spectra). It can be found that when $q<0, \tau(q)$ emerges an obvious increase trend with the increasing of $q$. In contrast, it emerges a slight increase when $q>0$. The changing trend of $\tau(q)$ at $q<0$ is much weaker than $q>0$. 


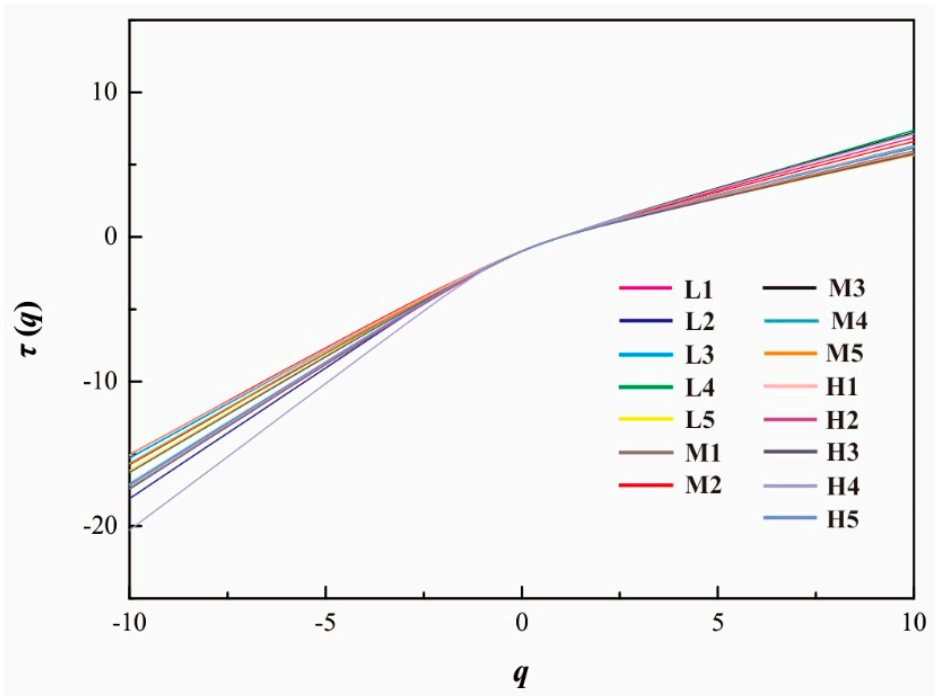

Figure 9. The relationship between the $\tau(q)$ and $q$.

\subsection{Petrophysical Characteristics and Multifractal Parameters}

Previous studies show that the multifractal parameters (i.e., $D_{\min }, D_{\max }$ and $\Delta \alpha$ ) can be used for describing the heterogeneity characterization of PSDs $[34,36]$. The parameters $D_{\min }$ and $D_{\max }$ are more sensitive to the heterogeneity of a low and high probability interval, respectively. In this study, the parameters $D_{\min }$ and $D_{\max }$ were chosen to investigate the relationship between petrophysical characteristics and heterogeneity characteristics.

The relationship between vitrinite and inertinite contents versus $D_{\min }$ and $D_{\max }$ are shown in Figure 10. The vitrinite and inertinite contents are positively and negatively correlated with $D_{\min }$, respectively, whereas they emerge as having no meaningful relationship with $D_{\max }$. As shown in Figure 11, the moisture and ash contents only show a negative relationship with $D_{\max }$, and no relationship with $D_{\min }$. The results indicate that the increase in moisture and ash content reduce the heterogeneity of the PSDs with a high probability interval. However, in Li et al. [38], they found there is no significant relationships between moisture and ash content with multifractal parameters. It is possible that the samples studied in Li et al. [38] are only the tectonically deformed coal which limits the analysis in other types of coals.

Figure 12 displays relationships of multifractal dimensions $\left(D_{\min }\right.$ and $\left.D_{\max }\right)$ vs. MIP parameters (injection of mercury saturation and efficiency of mercury withdrawal). $D_{\min }$ is negatively correlated with the injection of mercury saturation, whereas it shows no obvious correlation with the efficiency of mercury withdrawal. The $D_{\max }$ shows a "U-morph" relationship with the efficiency of mercury withdrawal, with a minimum value at $55 \%$, and it shows no relationship with the injection of mercury saturation. This may suggest that the multifractal dimension $D_{\max }$ is more sensitive to the efficiency of mercury withdrawal, while $D_{\min }$ is more sensitive to the injection of mercury saturation. 

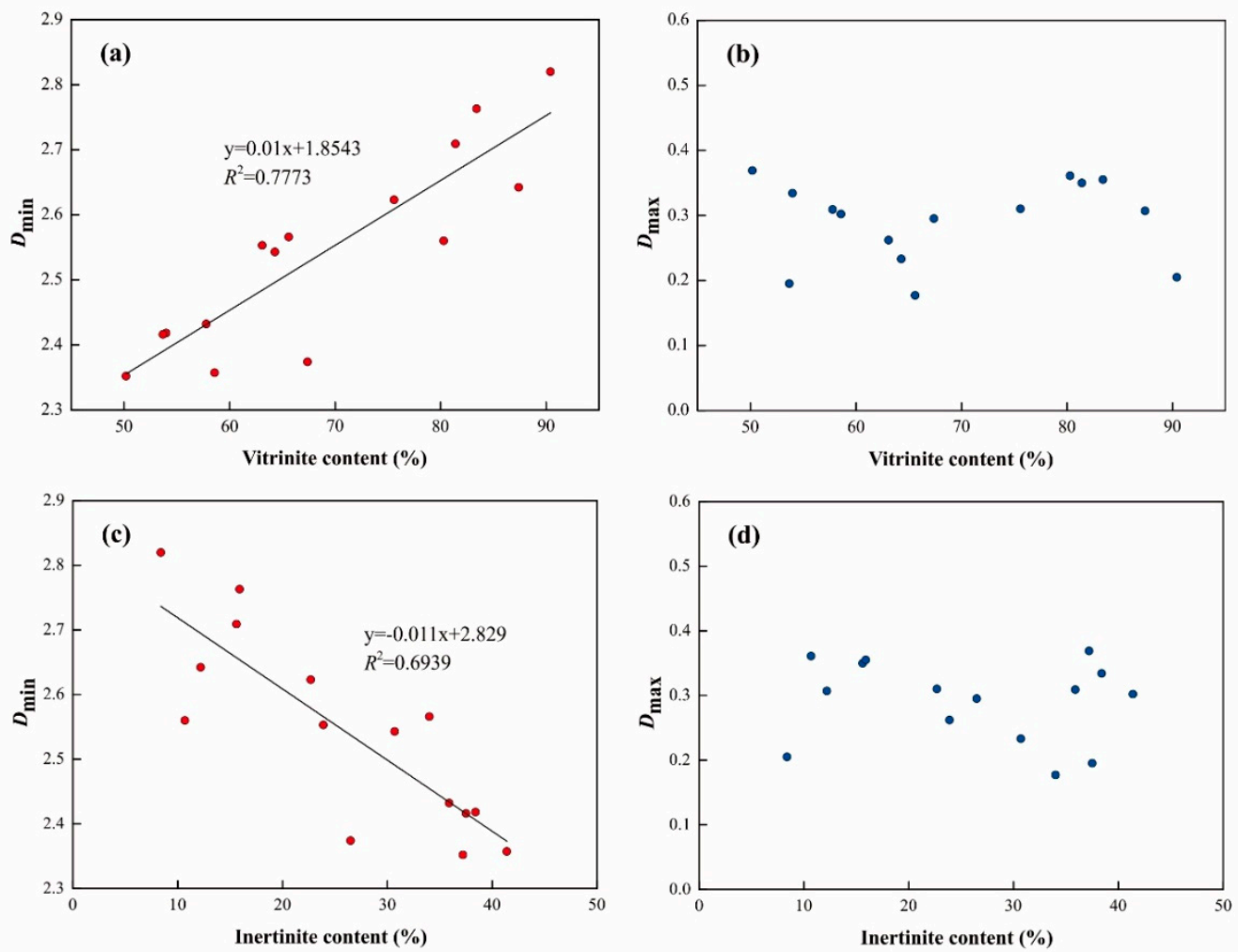

Figure 10. The cross plots of vitrinite and inertinite content versus multifractal parameter $D_{\min }$ and $D_{\max }$. (a) vitrinite content versus $D_{\min } ;(\mathbf{b})$ vitrinite content versus $D_{\max } ;$ (c) inertinite content versus $D_{\min } ;(\mathbf{d})$ inertinite content versus $D_{\max }$.
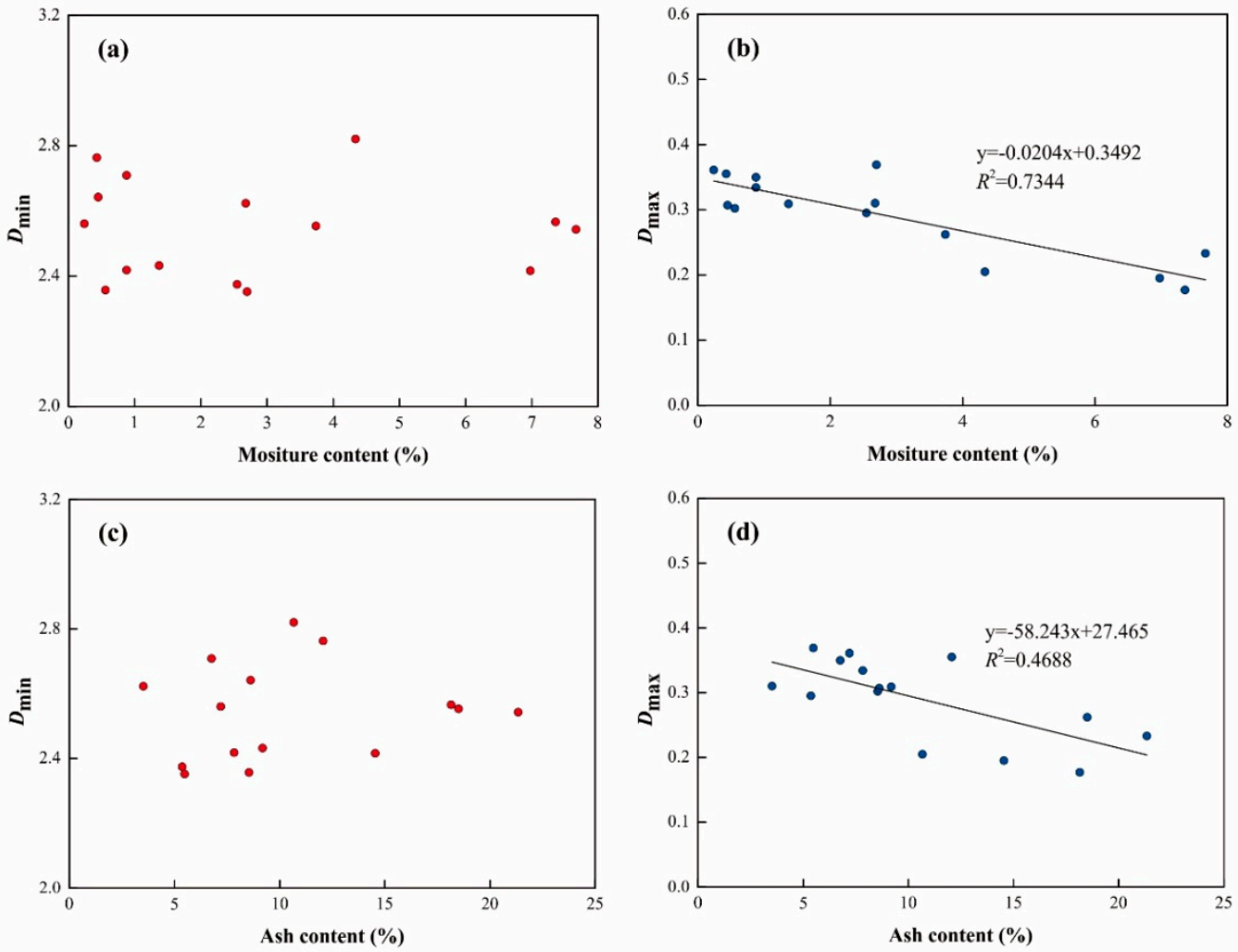

Figure 11. The cross plots of moisture and ash content versus multifractal parameter $D_{\min }$ and $D_{\max }$. (a) moisture content versus $D_{\min } ;(\mathbf{b})$ moisture content versus $D_{\max } ;(\mathbf{c})$ ash content versus $D_{\min } ;(\mathbf{d})$ ash content versus $D_{\max }$. 

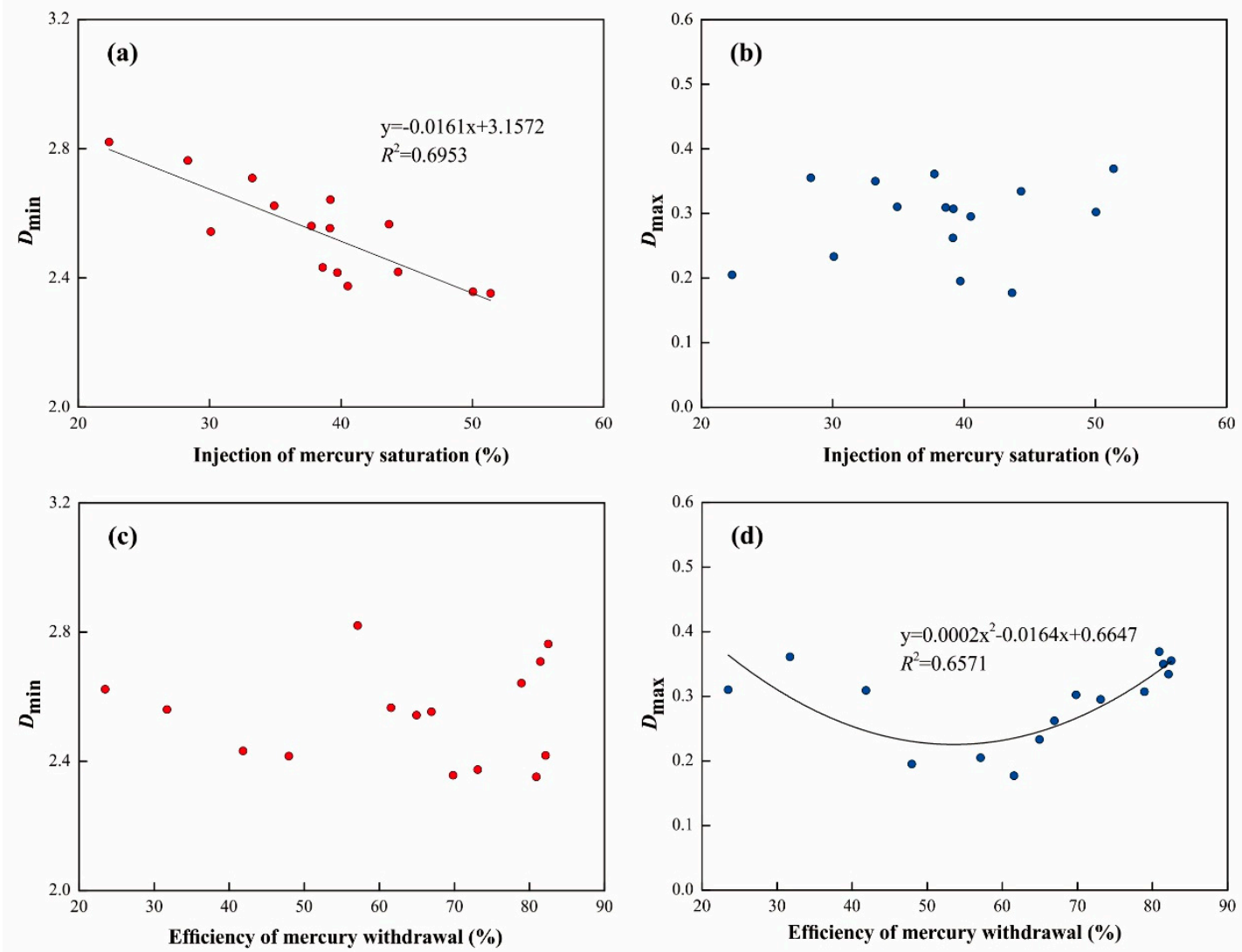

Figure 12. The cross plots of injection of mercury saturation and efficiency of mercury withdrawal versus multifractal parameter $D_{\min }$ and $D_{\max }$. (a) injection of mercury saturation versus $D_{\min }$; (b) injection of mercury saturation versus $D_{\max }$; (c) efficiency of mercury withdrawal versus $D_{\min }$; (d) efficiency of mercury withdrawal versus $D_{\max }$.

\section{Conclusions}

This study firstly combined MIP and LTNA data to correct the mercury intrusion volume under high pressure ranges. Then, the multifractal analysis was applied to characterize the variability and heterogeneity of the corrected PSDs in coals. The major conclusions made are as follows:

- Coal matrix compressibility has an evident impact on MIP data when the mercury intrusion pressure $>24.75 \mathrm{MPa}$. Combined with LTNA data, the MIP PSDs ranging between 3 and $25 \mathrm{~nm}$ was corrected. The corrected mercury intrusion volume decreased by $35.51-96.65 \%$. The matrix compressibility coefficients vary from $0.89 \times 10^{-10} \mathrm{~m}^{2} / \mathrm{N}$ to $2.47 \times 10^{-10} \mathrm{~m}^{2} / \mathrm{N}$, following a cubic polynomial relationship with the increasing $R_{\mathrm{o}, \mathrm{m}}$.

- The multifractal analysis of corrected PSDs, which were determined using a combination of MIP and LTNA data, was conducted. The multifractal spectrum shows a typical concave-down parabola shape. On the left of the parabola, $f(\alpha)$ increases with the increase of $\alpha(q)$. In contrast, $f(\alpha)$ decreases with the increase of $\alpha(q)$ on the right of parabola.

- When $q<0$, the mass exponent spectra emerges, showing an obvious increasing trend with the increase in $q$. In contrast, there is a slight increase when $q>0$. The multifractal spectra generalized dimensions and mass exponent spectra indicate the typical multifractal characteristics of corrected PSDs for the coals.

- Multifractal parameter $D_{\min }$ shows a negative relationship with inertinite contents and mercury intrusion saturation, whereas it shows a positive relationship with the vitrinite contents. $D_{\max }$ shows a negative relationship with moisture and ash content, and a "U-shaped" trend with efficiency of mercury withdrawal. 
Author Contributions: Y.Y. conceived and designed the experiments; S.Z. (Sijian Zheng) performed the experiment sand wrote the paper; S.Z. (Sijian Zheng) and S.Z. (Shasha Zhang) analyzed the data; Y.Y. and Y.L. revised the paper and provided language support; J.Y. provided technical support.

Funding: This research was funded by the National Natural Science Foundation of China (grant Nos. 41830427 and 41872123), the National Major Research Program for Science and Technology of China (grant No. 2016ZX05043-001), the Key research and development project of Xinjiang Uygur Autonomous Region (grant No. 2017B03019-1), and the Fundamental Research Funds for the Central Universities (292018227).

Conflicts of Interest: The authors declare no conflict of interest.

\section{References}

1. Moore, T.A. Coalbed methane: A review. Int. J. Coal Geol. 2012, 101, 36-81. [CrossRef]

2. Cai, Y.D.; Liu, D.M.; Pan, Z.J.; Yao, Y.B.; Li, J.Q.; Qiu, Y.K. Pore structure and its impact on $\mathrm{CH}_{4}$ adsorption capacity and flow capability of bituminous and subbituminous coals from Northeast China. Fuel 2013, 103, 258-268. [CrossRef]

3. Cai, Y.D.; Liu, D.M.; Yao, Y.B.; Li, J.Q.; Qiu, Y.K. Geological controls on prediction of coalbed methane of No. 3 coal seam in Southern Qinshui Basin, North China. Int. J. Coal Geol. 2011, 88, 101-112. [CrossRef]

4. Zheng, S.J.; Yao, Y.B.; Liu, D.M.; Cai, Y.D.; Liu, Y. Characterizations of full-scale pore size distribution, porosity and permeability of coals: A novel methodology by nuclear magnetic resonance and fractal analysis. Int. J. Coal Geol. 2018, 196, 148-158. [CrossRef]

5. Liu, X.F.; Nie, B.S. Fractal characteristics of coal samples utilizing image analysis and gas adsorption. Fuel 2016, 182, 314-322. [CrossRef]

6. Cai, Y.D.; Liu, D.M.; Mathews, J.P.; Pan, Z.J.; Elsworth, D.; Yao, Y.B.; Li, J.Q.; Guo, X.Q. Permeability evolution in fractured coal-Combining triaxial confinement with $\mathrm{X}$-ray computed tomography, acoustic emission and ultrasonic techniques. Int. J. Coal Geol. 2014, 122, 91-104. [CrossRef]

7. Yao, Y.B.; Liu, D.M.; Che, Y.; Tang, D.Z.; Tang, S.H.; Huang, W.H. Non-destructive characterization of coal samples from China using microfocus X-ray computed tomography. Int. J. Coal Geol. 2009, 80, 113-123. [CrossRef]

8. Golab, A.; Ward, C.R.; Permana, A.; Lennox, P.; Botha, P. High-resolution three-dimensional imaging of coal using microfocus $X$-ray computed tomography, with special reference to modes of mineral occurrence. Int. J. Coal Geol. 2013, 113, 97-108. [CrossRef]

9. Pan, J.N.; Zhu, H.T.; Hou, Q.L.; Wang, H.C.; Wang, S. Macromolecular and pore structures of Chinese tectonically deformed coals studied by atomic force microscopy. Fuel 2015, 139, 94-101. [CrossRef]

10. Wang, S.Q.; Liu, S.M.; Sun, Y.B.; Jiang, D.; Zhang, X.M. Investigation of coal components of Late Permian different ranks bark coal using AFM and Micro-FTIR. Fuel 2017, 187, 51-57. [CrossRef]

11. Wang, G.C.; Ju, Y.W.; Yan, Z.F.; Li, Q.G. Pore structure characteristics of coal-bearing shale using fluid invasion methods: A case study in the Huainan-Huaibei Coalfield in China. Mar. Pet. Geol. 2015, 62, 1-13. [CrossRef]

12. Song, Y.; Jiang, B.; Shao, P.; Wu, J.H. Matrix compression and multifractal characterization for tectonically deformed coals by $\mathrm{Hg}$ porosimetry. Fuel 2018, 211, 661-675.

13. Yao, Y.B.; Liu, D.M.; Tang, D.Z.; Tang, S.H.; Huang, W.H. Fractal characterization of adsorption-pores of coals from North China: An investigation on $\mathrm{CH}_{4}$ adsorption capacity of coals. Int. J. Coal Geol. 2008, 73, 27-42. [CrossRef]

14. Chen, Y.L.; Qin, Y.; Wei, C.T.; Huang, L.L.; Shi, Q.M.; Wu, C.F.; Zhang, X.Y. Porosity changes in progressively pulverized anthracite subsamples: Implications for the study of closed pore distribution in coals. Fuel 2018, 225, 612-622. [CrossRef]

15. Pajdak, A.; Kudasik, M.; Skoczylas, N.; Wierzbicki, M.; Teixeira Palla Braga, L. Studies on the competitive sorption of $\mathrm{CO}_{2}$ and $\mathrm{CH}_{4}$ on hard coal. Int. J. Greenh. Gas Con. 2019, 90, 102798. [CrossRef]

16. Kudasik, M.; Skoczylas, N.; Pajdak, A. The repeatability of sorption processes occurring in the coal-methane system during multiple measurement series. Energies 2017, 10, 661. [CrossRef]

17. Yao, Y.B.; Liu, J.; Liu, D.M.; Chen, J.Y.; Pan, Z.J. A new application of NMR in characterization of multiphase methane and adsorption capacity of shale. Int. J. Coal Geol. 2019, 201, 76-85. [CrossRef]

18. Yao, Y.B.; Liu, D.M.; Che, Y.; Tang, D.Z.; Tang, S.H.; Huang, W.H. Petrophysical characterization of coals by low-field nuclear magnetic resonance (NMR). Fuel 2010, 89, 1371-1380. [CrossRef] 
19. Zheng, S.J.; Yao, Y.B.; Liu, D.M.; Cai, Y.D.; Liu, Y. Nuclear magnetic resonance surface relaxivity of coals. Int. J. Coal Geol. 2019, 205, 1-13. [CrossRef]

20. Friesen, W.I.; Mikula, R.J. Mercury porosimetry of coals-Pore volume distribution and compressibility. Fuel. 1988, 67, 1516-1520. [CrossRef]

21. Yao, Y.B.; Liu, D.M. Comparison of low-field NMR and mercury intrusion porosimetry in characterizing pore size distributions of coals. Fuel 2012, 95, 152-158. [CrossRef]

22. Li, Y.; Lu, G.Q.; Rudolph, V. Compressibility and fractal dimension of fine coal particles in relation to pore structure characterisation using mercury porosimetry. Part. Part. Syst. Char. 1999, 16, 25-31. [CrossRef]

23. Guo, X.Q.; Yao, Y.B.; Liu, D.M. Characteristics of coal matrix compressibility: An investigation by mercury intrusion porosimetry. Energy Fuels 2014, 28, 3673-3678. [CrossRef]

24. Cai, Y.D.; Li, Q.; Liu, D.M.; Zhou, Y.F.; Lv, D. Insights into matrix compressibility of coals by mercury intrusion porosimetry and $\mathrm{N}_{2}$ adsorption. Int. J. Coal Geol. 2018, 200, 199-212. [CrossRef]

25. Mandelbrot, B.B. The Fractal Geometry of Nature; W. H. Freeman and Co.: New York, NY, USA, 1983 ; p. 495.

26. Pape, H.; Tillich, J.E.; Holz, M. Pore geometry of sandstone derived from pulsed field gradient NMR. J. Appl. Geophys. 2006, 58, 232-252. [CrossRef]

27. Jin, Y.; Zhu, Y.B.; Li, X.; Zheng, J.L.; Dong, J.B. Scaling invariant effects on the permeability of fractal porous media. Transp. Porous Media 2015, 109, 433-453. [CrossRef]

28. Chen, X.J.; Yao, G.Q.; Cai, J.C.; Huang, Y.T.; Yuan, X.Q. Fractal and multifractal analysis of different hydraulic flow units based on micro-CT images. J. Nat. Gas Sci. Eng. 2017, 48, 145-156. [CrossRef]

29. Zhao, Y.X.; Zhu, G.P.; Dong, Y.H.; Danesh, N.N.; Chen, Z.W.; Zhang, T. Comparison of low-field NMR and microfocus X-ray computed tomography in fractal characterization of pores in artificial cores. Fuel 2017, 210, 217-226. [CrossRef]

30. Krohn, C.E.; Thompson, A.H. Fractal sandstone pores: Automated measurements using scanning-electron-microscope images. Phys. Rev. B 1986, 33, 6366-6374. [CrossRef]

31. Peng, R.D.; Yang, Y.C.; Ju, Y.; Mao, L.T.; Yang, Y.M. Computation of fractal dimension of rock pores based on gray CT images. Chin. Sci. Bull. 2011, 56, 3346-3357. [CrossRef]

32. Gould, D.J.; Vadakkan, T.J.; Poché, R.A.; Dickinson, M.E. Multifractal and lacunarity analysis of microvascular morphology and remodeling. Microcirculation 2011, 18, 136-151. [CrossRef] [PubMed]

33. Ge, X.M.; Fan, Y.R.; Zhu, X.J.; Chen, Y.G.; Li, R.Z. Determination of nuclear magnetic resonance $T_{2}$ cutoff value based on multifractal theory-An application in sandstone with complex pore structure. Geophysics 2015, 80, 11-21. [CrossRef]

34. Ge, X.M.; Fan, Y.R.; Li, J.T.; Zahid, M.A. Pore structure characterization and classification using multifractal theory-An application in Santanghu Basin of western China. J. Pet. Sci. Eng. 2015, 127, 297-304. [CrossRef]

35. Bu, H.L.; Ju, Y.W.; Tang, J.Q.; Wang, G.C.; Li, X.S. Fractal characteristics of pores in non-marine shales from the Huainan coalfield, eastern China. J. Nat. Gas Sci. Eng. 2015, 24, 166-177. [CrossRef]

36. Zhao, P.D.; Wang, X.X.; Cai, J.C.; Luo, M.; Zhang, J.; Liu, Y.M.; Rabiei, M.; Li, C.C. Multifractal analysis of pore structure of Middle Bakken formation using low temperature $\mathrm{N}_{2}$ adsorption and NMR measurements. J. Pet. Sci. Eng. 2019, 176, 312-320. [CrossRef]

37. Zheng, S.J.; Yao, Y.B.; Liu, D.M.; Cai, Y.D.; Liu, Y.; Li, X.W. Nuclear magnetic resonance $T_{2}$ cutoffs of coals: A novel method by multifractal analysis. Fuel 2019, 241, 715-724. [CrossRef]

38. Li, W.; Liu, H.F.; Song, X.X. Multifractal analysis of Hg pore size distributions of tectonically deformed coals. Int. J. Coal Geol. 2015, 145, 138-152. [CrossRef]

39. Halsey, T.C.; Hensen, M.H.; Kadanoff, L.P.; Procaccia, I.; Shraiman, B.I. Scaling structure of the surface layer of diffusion-limited aggregates. Phys. Rev. 1986, 33, 1141-1151. [CrossRef]

40. Shao, P.; Wang, X.; Song, Y.; Li, Y. Study on the characteristics of matrix compressibility and its influence factors for different rank coals. J. Nat. Gas Sci. Eng. 2018, 56, 93-106. [CrossRef]

41. Debelak, K.A.; Schrodt, J.T. Comparison of pore structure in Kentucky coals by mercury penetration and carbon dioxide adsorption. Fuel 1979, 58, 732-736. [CrossRef]

42. Xu, L.; Liu, C.; Xian, X.; Zhang, D. Compressibility of coal matter and coal pore. Colloids Surf. A Physicochem. Eng. Aspect. 1999, 157, 219-222. [CrossRef]

43. Zhang, B.; Liu, W.; Liu, X. Scale-dependent nature of the surface fractal dimension for bi- and multi-disperse porous solids by mercury porosimetry. Appl. Surf. Sci. 2006, 253, 1349-1355. [CrossRef] 
44. Yao, Y.B.; Liu, D.M.; Tang, D.Z.; Tang, S.H.; Huang, W.H.; Liu, Z.H.; Che, Y. Fractal characterization of seepage-pores of coals from China: An investigation on permeability of coals. Comput. Geosci. 2009, 35, 1159-1166. [CrossRef]

45. Caniego, J.; Martin, M.A.; San, J.F. Singularity features of pore-size distribution: Singularity strength analysis and entropy spectrum. Fractals 2001, 9, 305-316. [CrossRef]

46. Tarquis, A.; Giménez, D.; Saá, A.; Díaz, M.C.; Gascó, J.M. Scaling and multiscaling of soil pore systems determined by image analysis. In Scaling Methods in Soil Physics; Pachepsky, Y., Radcliffe, D.E., Magdi Selim, H., Eds.; CRC Press: Boca Raton, FL, USA, 2003; p. 434.

(C) 2019 by the authors. Licensee MDPI, Basel, Switzerland. This article is an open access article distributed under the terms and conditions of the Creative Commons Attribution (CC BY) license (http://creativecommons.org/licenses/by/4.0/). 